\title{
DEATH-FEIGNING IN THE \\ EASTERN YELLOW-BELLIED RACER
}

WAYNE LYNCH, 1762 Kilborn Avenue, Ottawa, Ontario K1H 6W2

At midmorning on October 15, 1977 Gary Seib and I visited a hibernaculum $7 \frac{1}{2}$ miles south-east of Val Marie, Saskatchewan. Despite the cool temperature $\left(45^{\circ} \mathrm{F}\right)$ we found a pair of eastern yellow-bellied racers (Coluber constrictor flaviventris) sunning at the mouth of the den. When we captured one, it writhed vigorously, discharging secretions from its cloacal glands and several times assumed a threatening pose with its mouth gaping. The initial resistance was shortlived and it settled within minutes. After handling for 20 minutes we released the racer on the ground where it rolled on its back exposing the distal two-thirds of its yellow underside. For 30 seconds it remained motionless in this pose before slowly moving off. Upon recapture it repeated the display which again lasted half a minute. Subsequent release and capture failed to stimulate further death-feigning. Once replaced at the mouth of the hibernaculum the racer required prodding before disappearing into the den.

All animals require that behavior be adaptive for survival. Of the 23 species of snakes in Canada, however, only the hognose snake (Heterodon) regularly includes death-feigning in its repertoire. The death-feign is just one part of a three phase response seen in snakes that use this technique to confuse predators. The first phase, erratic behavior, surprises predators and hopefully foils their attack. In

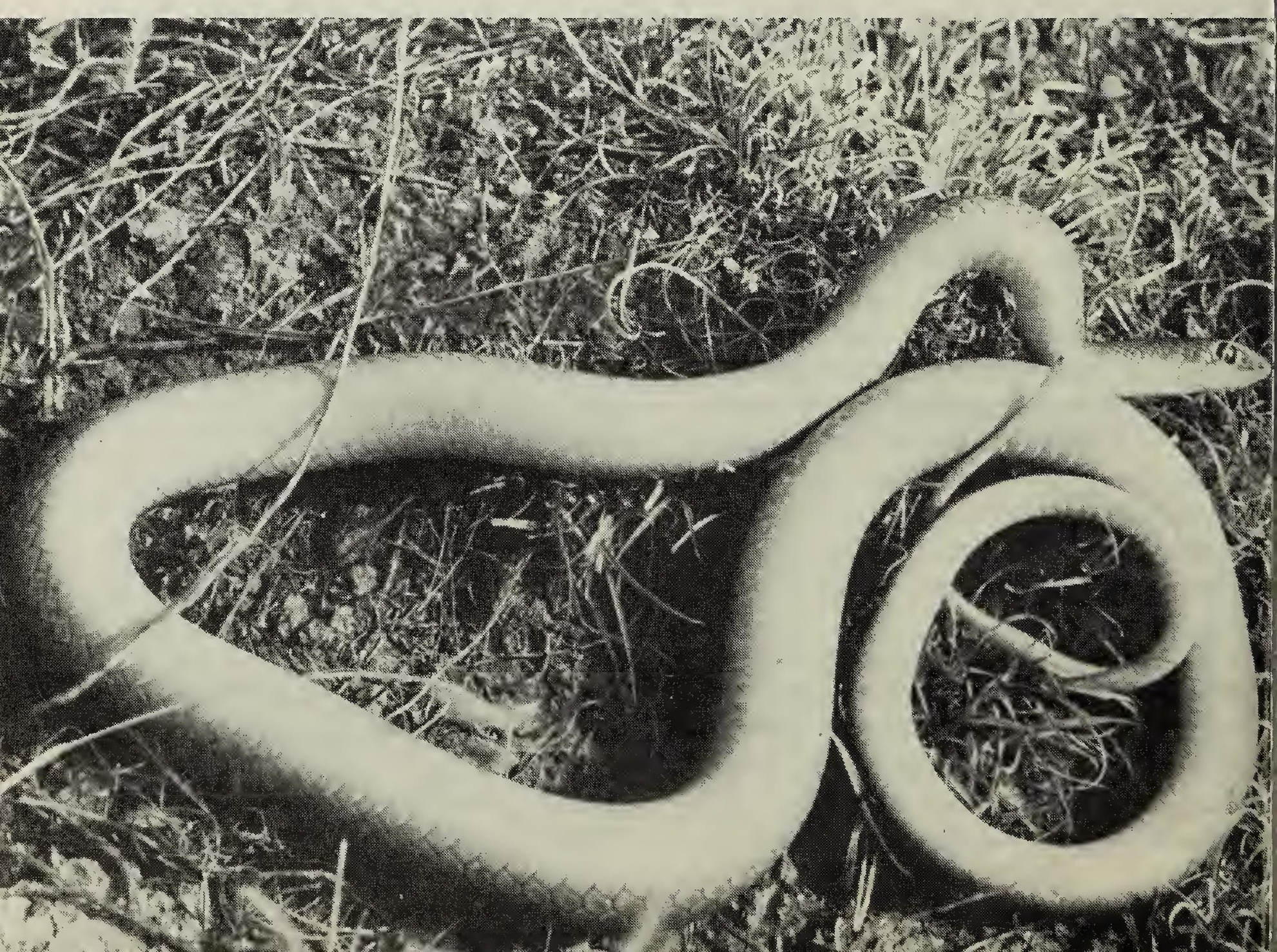




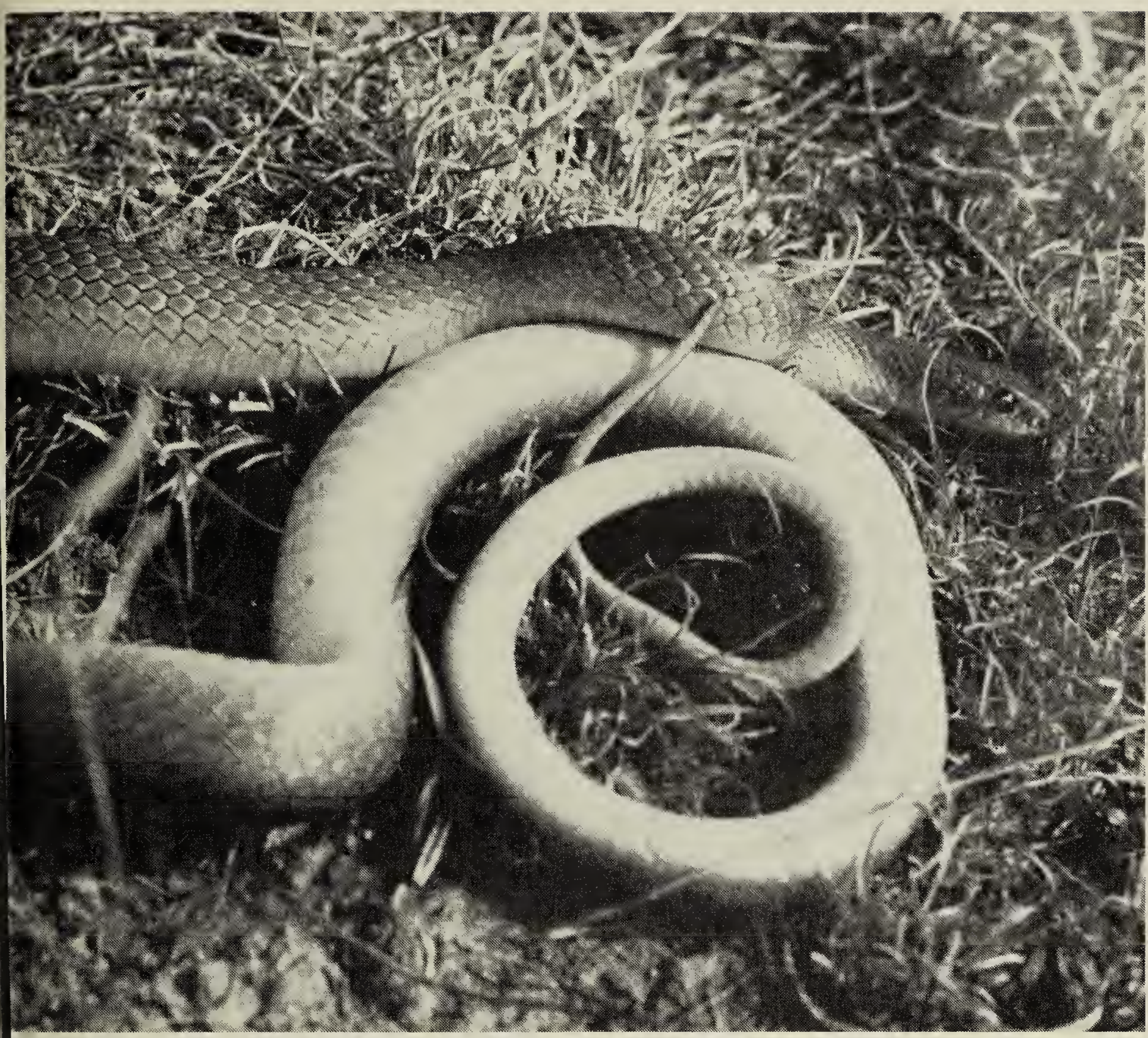

Death-feigning in the Eastern Yellow-bellied Dancer

Wayne Lynch

addition, the noxious secretions produced by the cloacal glands are pread more effectively as the snake hrashes about. Tactile stimulation usually initiates this phase but visual and olfactory clues may also stimulate response in some species. The second phase is the death-feign. The final hase is cautious recovery. It seems hat it is not the death-feign itself that auses predators to release their prey ut the sudden shift from erratic ehavior to a motionless state. jehlbach illustrated this point using ingsnakes (Lampropeltis), a species hat commonly preys on other snakes. ${ }^{2}$ snake offered in a death-feign was sually eaten whereas one that ehaved in the entire three phase quence was captured and generally released. Thereafter, snakes usually attempt escape but will repeat the death-feign if touched, especially on the head.

Fitch has described erratic behavior in the eastern yellow bellied racer but death feigning was not previously reported in this species.

'FITCH, H. S. 1963. The Natural History of the Racer Coluber constrictor. The Univ. of Kansas Mus. of Nat. Hist. Pub. 15, pp. 351-468.

${ }^{2} \mathrm{GEHLBACH}$, FREDERICK. 1970. DeathFeigning and Erratic Behavior in Leptotyphlopid, Colubrid and Elapid Snakes. Herpetologica 26(1):24-34. 